\title{
CARACTERISTICAS DE CEPAS CHILENAS DE Pyrenochaeta lycopersici Y PERSPECTIVAS DE CONTROL BIOLOGICO
}

\author{
(Characteristics of chilean Pyrenochaeta lycopersici strains and \\ perspectives of biological control)
}

*Besoain, X.A.; *Pardo, G.; *Raggi, C.;*Opazo, M.; *Araya, S.; **Perez, L.M.; ***Montealegre, J. *Laboratorio de Fitopatología, Facultad de Agronomía, Pontificia Universidad Católica de Valparaíso. **Laboratorio de Bioquímica, Facultad de Ciencias de la Salud,Universidad Nacional Andrés Bello. ***Departamento de Sanidad Vegetal, Facultad de

Ciencias Agronómicas,Universidad de Chile.

Palabras clave: Pyrenochaeta lycopersici, cepas chilenas, control biológico Key words:Pyrenochaeta lycopersici, chilean strain,biological control

\author{
RESUMEN
}

Raíz corchosa es una de las principales enfermedades que afecta al cultivo de tomate que se produce bajo invernadero frio en Chile. En esta investigación se entregan antecedentes referentes a las principales características reproductivas de su agente causal, Pyrenochaeta lycopersici, como: picnidios, conidióforos y conidios. Además, antecedentes sobre la estrategia de control biológico de esta enfermedad. En base a estudios preliminares, se determinó a Trichoderma harzianum, como el taxa más promisorio (según cultivos duales). Se caracterizaron cepas de ambas especies de acuerdo a crecimiento micelial a diferentes temperaturas, $\mathrm{pH}, \mathrm{y}$ salinidad ( $\mathrm{NaCl}$ ). Finalmente, se efectuó un ensayo bajo condiciones controladas de invernadero, destacándose la cepa Th11 como la más promisoria en el biocontrol de este patógeno.

\section{INTRODUCCION}

Raíz corchosa o "corky root", es una importante enfermedad que afecta al cultivo de tomate, tanto a nivel mundial como en Chile. En nuestro país, esta patología se encuentra asociada principalmente al cultivo de tomate bajo invernaderos fríos, donde existe una condición de monocultivo. De acuerdo a estudios previos, esta enferme-
ABSTRACT

Corky root is one of the main diseases affecting tomato plantation carried out inside a cold greenhouse in Chile. In this research work information related to the main reproductive characteristics of its causing agent, Pyrenochaeta lycopersici such as: picnidia, conidiophores and conidia is given, together with some antecedents regarding the strategy of biological control of this disease. Based on preliminary studies, Tricho-derma harzanium was determined to be the most promissory taxa (according to dual cultures). Strains from both species were identified according to mycelial growth, different temperatures, $\mathrm{pH}$ and salinity $(\mathrm{NaCl})$. Finally an assay under controlled conditions of green-house was performed resulting Th11 as the most promissory strain in the biocontrol of this pathogen.

dad que induce a la pérdida temprana de raicillas y a una suberización severa de raíces principales, se determinó su agente causal, luego de un largo período en que se denominó como "hongo gris estéril" (GSF). Posteriormente se clasificó como Pyrenochaeta lycopersici por Schneider \& Gerlach en 1964 (Schneider \& Gerlach, 1966), y como patógeno secundario a Colletotrichum coccodes por Last \& Eben (1966). En nuestro país, Olavarria \& Besoain (1991), 
determinan a $\boldsymbol{P}$. lycopersici como causante de esta enfermedad, siendo confirmado por Araya (1994), quien además demostró la patoge-nicidad de $\boldsymbol{C}$. coccodes. Sin embargo, hasta la fecha no han sido publicados nuevos antecedentes etiológicos sobre esta importante enfermedad.

De acuerdo con ensayos efectuados a nivel de campo (González, 1991), es posible establecer pérdidas económicas asociadas a la enfermedad, principalmente para el cultivo temprano de primavera o "primor", debido a la presencia de bajas temperaturas de suelo. De acuerdo a estudios efectuados por Campbell et al. (1982), y en nuestro país por Duimovic (1991), la mejor estrategia para el control de esta enfermedad es el empleo de bromuro de metilo combinado con cloropicrina. Por otro lado, Montealegre et al. (1995), demuestran la efectividad de la solarización como estrategia de control, pero se dificulta su realización, ya que debe ser efectuada durante el mes de diciembre que es uno de los meses más productivos. En estos últimos años y sobre todo considerando la necesidad de reemplazar el uso del bromuro de metilo, surge la necesidad de buscar alternativas al control de este problema, como la estrategia de control biológico. A nivel mundial no ha sido posible encontrar mayores antecedentes sobre esta estrategia de control, a excepción de una reciente publicación (Pérez et al., 2003) la que es complementaria al presente artículo.

Este trabajo integra diversos estudios nacionales realizados entre los años 1993 y 2001 (no publicados), que aportan antecedentes etiológicos sobre la enfermedad raíz corchosa del tomate causada por Pyrenochaeta lycopersici Schneider y Gerlach y del efecto biocontrolador que poseen diversas cepas de Trichoderma harzianum, tanto bajo condiciones in vitro como controladas en invernadero.

\section{MATERIALES Y METODOS}

\section{Orígen de las cepas previamente aisladas.}

Con el propósito de determinar la incidencia de esta enfermedad y caracterizar cepas de $\boldsymbol{P}$. lycopersici a nivel de la Provincia de Quillota, donde los tomates han sido tradicionalmente cultivados. Se realizó durante la temporada de crecimiento del año 1993 una prospección que abarcó 17 predios de las comunas de La Calera, La Cruz, Limache, Olmué y Quillota, elegidos al azar de una base de datos. De cada predio, se colectaron dos muestras, a modo de realizar aislamientos desde raíces con síntomas de la enfermedad. De este modo se obtuvieron segmentos de $1 \mathrm{~cm}$ de largo, desde la zona de avance de las lesiones corchosas, las que fueron asépticamente desinfectadas (con hipoclorito de sodio al 1\%, por 2 minutos), seguidos por dos sucesivos lavados con agua destilada estéril (ADE), secados para ser posteriormente sembrados en
Agar-papa-dextrosa acidulado (APDA) y en "Corky Root Médium" (CRM) desarrollado por Grove y Campbell (1987), e incubadas a $22{ }^{\circ} \mathrm{C}$ por un mínimo de 7 días. Una vez obtenido el desarrollo de un micelio gris a gris verde, de lento crecimiento y estéril, o micelio inicialmente de color anaranjado tornándose luego de color gris oscuro y con microesclerocios, se repicó en APDA. Una vez obtenidos los cultivos puros, se identificaron mediante la metodología descrita por Clearjeau y Conus (1974). La que consiste básicamente en depositar sobre raicillas de melón, previamente pregerminadas bajo condiciones de asepsia en placas petri de $15 \mathrm{~cm}$ de diámetro, trozos de agar más micelio ( $3 \mathrm{~cm}$ de diámetro), sellándose las placas con Parafilm, manteniendose bajo luz negra $(320 \mathrm{~nm})$ en forma continuada, por al menos 30 días. Dentro de los primeros 15 días se observó el desarrollo de acérvulos correspondientes a Colletotrichum coccodes, mientras que al final de este período se desarrollaron los característicos picnidios setosos correspondientes a P.lycopersici, clasificándose un total de 16 cepas (Tabla 2, bajo la numeración 1-16). Posteriormente se prospectaron 5 predios de la comuna de Quillota, obteniéndose 5 cepas de $\boldsymbol{P}$. lycopersici, las que fueron identificadas de acuerdo con la metodología antes descrita (Tabla 2, bajo numeración 17-21)(Araya 1994; Opazo, 1997; Raggi, 2001).

Para la caracterización se efectuaron mediciones a 50 conidios, 10 conidióforos, picnidios y setas para cada aislado.

\section{Cultivos duales Trichoderma-Pyrenochaeta.}

Ambos tipos de cepas fueron obtenidos desde predios con más de 5 años de monocultivo de tomate, obteniéndose 18 cepas de Trichoderma (14 T. harzianum y 4 de $T$. koningii ), clasificadas anteriormente por Opazo (1997), las que fueron aisladas desde suelos con antecedentes de supresividad a raíz corchosa. Luego, se procedió a efectuar cultivos duales, con el propósito de evaluar el efecto de inhibir el crecimiento micelial de éstos contrastándolos con 5 cepas de $\boldsymbol{P}$. lycopersici (Pyr1, Pyr 2, Pyr 3, Pyr 4 y Pyr 5, Raggi, 2001). Para tal efecto se sembró en forma equidistante dos trozos de micelio de $P$. lycopersici en placas con APD, las que fueron selladas e incubadas a $22{ }^{\circ} \mathrm{C}$ por 6 días, sembrándose en forma opuesta en la misma placa dos trozos de micelio de cada cepa de Trichoderma a evaluar. Por cada cultivo dual se efectuaron cuatro repeticiones, efectuándose un tratamiento control consistente en el desarrollo de discos de micelio de cada cepa de $\boldsymbol{P}$. lycopersici. Se empleó un diseño estadístico completadamente al azar, realizándose un análisis de comparación de medias mediante el test de Tukey, con un nivel de significancia del 5\%. A partir de la información así obtenida, se procedió a seleccionar las 10 mejores cepas (Figura 2) capaces de lograr una significativa inhibición 
un análisis de comparación de medias mediante el test de Tukey, con un nivel de significancia del $5 \%$. A partir de la información así obtenida, se procedió a seleccionar las 10 mejores cepas (Figura 2) capaces de lograr una significativa inhibición del crecimiento micelial de 5 cepas de $\boldsymbol{P}$. lycopersici.

Características de $\mathbf{T}^{\circ}, \mathrm{pH}$ y Salinidad de cepas de $\boldsymbol{P}$. lycopersici y $T$. harzianum.

Con el propósito de caracterizar cepas de Pyrenochaeta y Trichoderma y correlacionar su posible comportamiento bajo condiciones de suelos de la provincia de Quillota,V Región, se determinó durante el año 2000 en el Laboratorio de Fitopatología de la Fac. de Agronomía de la Pont. Un. Católica de Valparaíso,el efecto de la temperatura, la salinidad y $\mathrm{pH}$ en el crecimiento micelial de éstos hongos. Todos éstos fueron evaluados mediante la siembra en APD de trozos de micelio de 5 $\mathrm{cm}$ de diámetro obtenidos desde cultivos puros, tanto de 3 cepas de Trichoderma harzianum (TH V, TH 11 y TH 291) como 5 de Pyrenochaeta lycopersici (P1240, P1242, P1243, P1245 y P1409), previamente obtenidas por Opazo (1997) y Raggi (2001), las que fueron debidamente identificadas, de acuerdo a metodología antes descrita (Clearjeau \& Conus (1974), y conservadas en ADE a 5 ${ }^{\circ} \mathrm{C}$. Para evaluar el efecto de las temperaturas se incubaron a intervalos de $5^{\circ} \mathrm{C}$, en el rango comprendido entre 5 y $35^{\circ} \mathrm{C}$, empleándose 3 repeticiones por cepa de cada especie. Para tal efecto se emplearon cámaras de incubación marca Precision Scientific, para los rangos de temperatura bajo ambiente. Para evaluar el efecto del $\mathrm{pH}$ se emplearon placas con medio APD, ajustado después de autoclavar a distintos $\mathrm{pH}$ con $\mathrm{HCL}$ o $\mathrm{KOH}$, en rangos de 5,5 a 8,5 con intervalos de medio punto. El rango óptimo de salinidad se evaluó sembrando las distintas cepas en APD ajustando el medio con distintas concentraciones de sales en el rango comprendido entre 0 y 250 $\mathrm{mM}$ de $\mathrm{NaCl}$, con intervalos de $50 \mathrm{mM}$.

\section{Ensayo de invernadero.}

Con el propósito de evaluar la efectividad de 3 cepas de Trichoderma (Th11, Th12 y Th16) las que habían sido previamente selecionadas por Opazo (1997)en controlar la raíz corchosa del tomate, se diseño un ensayo bajo condiciones controladas de invernadero. Ante la dificultad de inocular artificialmente $\boldsymbol{P}$. lycopersici, se empleó para este ensayo suelo naturalmente infectado perteneciente a un predio de la localidad de Santa Olivia, el que poseía antecedentes de ataque de raíz corchosa, monocultivo de tomate por más de 5 años y ausencia de tratamientos químicos. El suelo empleado poseía las siguientes características: Textura franco arcillosa, pH: 7,72 , conductividad eléctrica $3,0(\mathrm{mmhos} / \mathrm{cm})$, materia orgánica 5,92 .

El ensayo de efectuó en un invernadero de policarbonato con control de las condiciones ambientales de temperatura mediante aire acondicionado tipo ventana (Panasonic) de 24.000 BTU, con control automático de temperatura. Este además poseía sombreado con malla rashell negra, a modo de obtener condiciones favorables de temperatura para el desarrollo de raíz corchosa (Las temperaturas medias ambientales oscilaron entre 11 y $24^{\circ} \mathrm{C}$, y las temperaturas medias de suelo entre $10 \mathrm{y}$ $22^{\circ} \mathrm{C}$ ).

Las plantas de tomate cv. Fortaleza fueron desarrolladas en macetas de 3 litros de volumen, las que contenían suelo naturalmente infectado (antes descrito). Las plantas antes de ser transplantadas, fueron inoculadas al contenedor mediante metodología descrita por Sivan, et al.(1987), esta consistió en aplicar una mezcla de turba más salvado de trigo a razón 1:1 (v/v). La cantidad aplicada se midió volumétricamente en un vaso precipitado de 1 litro, agregándose a esta mezcla $200 \mathrm{ml}$ de ADE, y luego esterilizada mediante autoclave en bolsas de rafia, por 3 veces en forma consecutiva. Luego, la cepa de Trichoderma a inocular se sembró mediante la adición de 7 trozos de micelio de $0,5 \mathrm{~mm}$ de diámetro en el medio líquido MS (Okon, et al., 1973), luego de 48 horas de crecimiento micelial en este medio, se homogenizó la muestra y se contabilizó la cantidad de conidios/ml mediante un hematocitómetro de Bauer, empleándose_una concentración entre $0,72-2,5 \times 10^{7}$ conidios $/ \mathrm{ml}$. Esta suspensión fue incorporada a 3 frascos de turba $(900 \mathrm{ml}$ de capacidad) para cada cepa, incorporándose a cada una 166 $\mathrm{ml}$ del medio líquido MS con el micelio en crecimiento.

Tabla 1. Tratamientos efectuados en plantas de tomate en macetas, en base a dos dosis de tres cepas de $\boldsymbol{T}$. harzianum, incorporados al estado de plántula, y contrastado con tratamiento testigo y tratamiento estándar (bromuro de metilo); aplicados a suelo naturalmente infectado con $P$. lycopersici.

\begin{tabular}{|c|c|}
\hline $\begin{array}{c}\text { Trata- } \\
\text { miento }\end{array}$ & \multicolumn{1}{c|}{ Descripción } \\
\hline T0 & Testigo (turba con salvado de trigo) \\
\hline T1 & Bromuro de metilo (dosis $\left.70 \mathrm{~g} / \mathrm{m}^{2}\right)$ \\
\hline T2 & Cepa Th11 (dosis $5 \%)$ \\
\hline T3 & Cepa Th11 (dosis $10 \%)$ \\
\hline T4 & Cepa Th12(dosis $5 \%)$ \\
\hline T5 & Cepa Th12(dosis $10 \%)$ \\
\hline T6 & Cepa Th $16($ dosis $5 \%)$ \\
\hline T7 & Cepa Th $16($ dosis $10 \%)$ \\
\hline
\end{tabular}


Los frascos fueron sellados con Parafilm, e incubados en cámara de crecimiento con régimen lumínico de 12 horas a 6000 lux y 12 horas oscuridad, permaneciendo por 15 días a temperatura de $27^{\circ} \mathrm{C}$. Una vez finalizado este proceso se obtuvo el sustrato para la realización del ensayo de invernadero. Este sustrato fue la base para la incorporación de turba más Trichoderma en dosis de 5 y $10 \%(\mathrm{v} / \mathrm{v})$, combinada con turba más perlita (relación $1: 1$ ) marca Sunshine. Al tercer día de realizada esta labor, el sustrato fue humedecido, repicándose las semillas previamente pre-germinadas en estufa incubadora a $22^{\circ} \mathrm{C}$ por 48 horas. El almácigo fue realizado bajo condiciones controladas de invernadero, efectuándose el transplante a los 45 días a macetas con suelo naturalmente infectado con $\boldsymbol{P}$. lycopersici. Los tratamientos empleados se presentan en Tabla 1.

\section{RESULTADOS Y DISCUSIÓN}

Obtención de las cepas.

De acuerdo a los resultados obtenidos en la pros- pección a diferentes predios con cultivo de tomate bajo invernadero, de la provincia de Quillota, se obtuvo desde todos los predios prospectados aislamientos de micelio gris estéril, caracterizándose un total de 16 aislados como P. lycopersici.(Tabla 2). En medio CRM las colonias se desarrollaron en 7 días, presentando un crecimiento lento, aunque al ser traspasadas a APD cubrian las placas Petri en seis a ocho días.

La metodología propuesta por Clearjeau (1974), permitió al cabo de un mes de incubación en raíces de melón el desarrollo de los característicos picnidios setosos, solitarios y globosos correspondientes al género Pyrenochaeta. Estos presentaron un notorio ostíolo, con células melanizadas, más oscuras alrededor del cue110 , con 8 a más de 50 setas septadas y melanizadas de color café oscuro. Las células de las paredes de los picnidios se caracterizaron también por presentar una fuerte pigmentación. Al interior del picnidio, las células de la pared interna se presentaban casi hialinas: conidioforos largos, filiformes, ramificados a veces er la base, multiseptados, hialinos, que se forman desde las células internas de la pared del conidioma, célula:

Tabla 2. Dimensión de estructuras fúngicas de $P$. lycopersici, correspondientes a aislados obtenidos de raíces corchosas de tomates cultivados bajo invernadero frío

\begin{tabular}{|c|c|c|c|c|c|}
\hline Ariblado & $\begin{array}{l}\text { Loralidad y comma } \\
\text { de V Region }\end{array}$ & $\begin{array}{l}\text { Comiatios } \\
\text { Larno y } \\
\text { and ho (uon) }\end{array}$ & $\begin{array}{l}\text { Coniditóforo } \\
\text { (largo oum) }\end{array}$ & $\begin{array}{c}\text { Seta } \\
\text { Gargo } \mathrm{km} \text { ) }\end{array}$ & $\begin{array}{l}\text { Picnitio } \\
\text { (ancho y alto } \\
\text { (im) }\end{array}$ \\
\hline 1 & Lo Grmboa, Limache & $4,4 \times 2,4$ & 30,6 & 1583 & $288,5 \times 311,5$ \\
\hline 2 & Lo Gambos, Limache & $4,4 \times 18$ & 27,6 & 580 & $2826 \times 55,1$ \\
\hline 3 & Lo Gambos, Limache & $4,7 \times 25$ & 229 & 728 & $2474 \times 2764$ \\
\hline 4 & La Palma, Ouvillots & $40 \times 19$ & 399 & $127 ?$ & $3788 \times 3058$ \\
\hline 5 & La Palma, Quillota & $4,1 \times 2,2$ & 26,8 & $51 \rho$ & $1885 \times 1608$ \\
\hline 6 & Sants Olivia, Ouillots & $39 \times 21$ & 325 & 1421 & $3018 \times 2696$ \\
\hline 7 & Samts Olivia, Quillota & $3,7 \times 2,1$ & $34, ?$ & 1792 & $3072 \times 303,4$ \\
\hline 8 & Sam Isidro, Quillota & $4,1 \times 1,4$ & 323 & 1397 & $1185 \times 1712$ \\
\hline 9 & Sm Isidro, Quillota & $4,1 \times 29$ & 43,0 & 2171 & $2346 \times 2373$ \\
\hline 10 & Sam Isitro, Quillots & $42 \times 29$ & 27,6 & 796 & $2830 \times 2508$ \\
\hline 11 & San Isilro, Quillota & $43 \times 19$ & 41,5 & 1639 & $2654 \times 2827$ \\
\hline 12 & Sm Isitro, Quillots & $46 \times 27$ & 48,0 & 1527 & $2615 \times 2835$ \\
\hline 13 & Sm Isilm, Quillota & $4,4 \times 26$ & 49,1 & $84, ?$ & $2402 \times 2306$ \\
\hline 14 & Sam Isidro, Quillota & $4,2 \times 21$ & 43,0 & 1129 & $2308 \times 3350$ \\
\hline 15 & Quillota, Quillota & $4,5 \times 15$ & $26, ?$ & 1545 & $2827 \times 250 \rho$ \\
\hline 16 & Quillota, Quilbta & $45 \times 15$ & 44,4 & 97,1 & $3382 \times 2812$ \\
\hline 17 & Ouillota, Quillots & $50 \times 23$ & 30.5 & 610 & No me dido \\
\hline 18 & Quillota, Quillots & $4,8 \times 23$ & 36,0 & 1217 & No me dido \\
\hline 19 & Ouillots, Quillots & $4.6 \times 23$ & 40.7 & 118.5 & Fo me dido \\
\hline 20 & Quillota, Quilbta & $4,86 \times 25$ & 412 & 2138 & No me dido \\
\hline 21 & Quillota, Quillots & $42 \times 20$ & 378 & 912 & No me dido \\
\hline Promedio & & $4,36 \times 1,99$ & 36,0 & 1236 & \\
\hline
\end{tabular}


conidiógenas fialídicas integradas que nacen como cortas ramas inmediatamente bajo los septos transversales, hialinas sin un collarete conspicuo, conidios hialinos aseptados, lisos, cilindricos a elipsoidales con 2 gutulas características en cada extremo. De acuerdo a las observaciones efectuadas a las diversas estructuras reproductivas más sus respectivas dimensiones (Tabla 2), fue posible clasificar a los aislados chilenos como pertenecientes a la especie P.lycopersici Schneider \& Gerlach. Si bien esta descripción se ajusta a las dimensiones originalmente señaladas por CMI (Punithalinham \& Holliday, 1973), existe discrepancia, ya que de acuerdo con Sutton (1980), los conidios deberían ser ligeramente superiores (rango de 5 a $7 \mu \mathrm{m}$ ). Esta diferencia puede corresponder a ecotipos diferentes (por condiciones geográficas) a las descritas originalmente por Schneider \& Gerlach (1966). Sin embargo, existe concordancia en las mediciones de las setas y conidióforos descritas por (Cleaujeau \& Conus (1974) y Sutton (1980).

Por otro lado, tanto durante los cultivos desarrollados en otoño como en primavera, fue posible aislar también el agente secundario $C$. coccodes, existiendo un mayor porcentaje de recuperación en el cultivo de otoño, él que cuenta en sus inicios con temperaturas de suelo más elevadas.

\section{Cultivos duales.}

El grado de inhibición promedio del crecimiento de 5 cepas de Pyrenochaeta al ser contrastadas con 10 cepas de Trichoderma, se presenta en Figura 2. Un aspecto importante de considerar es que de las 18 cepas aisladas desde suelos con cultivo de tomates supresivos a raíz corchosa perteneciente al género Trichoderma, las que fueron capaces de disminuir en forma significativa el desarrollo micelial de $\boldsymbol{P}$. lycopersici, correspondieron todas a la especie T.harzianum (Figura 2). En estudio com-

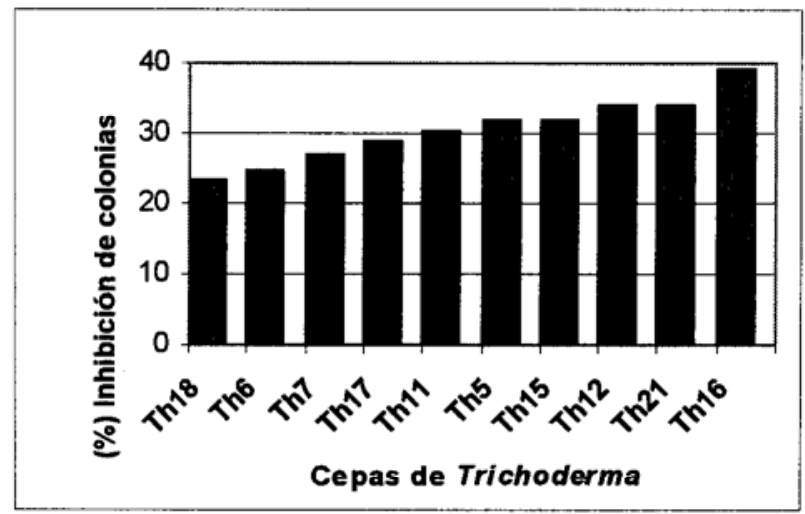

Figura 2. Porcentaje de inhibición del área de crecimiento micelial mediante cultivo dual entre colonias de P.lycopersici (promedio de 5 cepas) y 10 cepas de T.harzianum

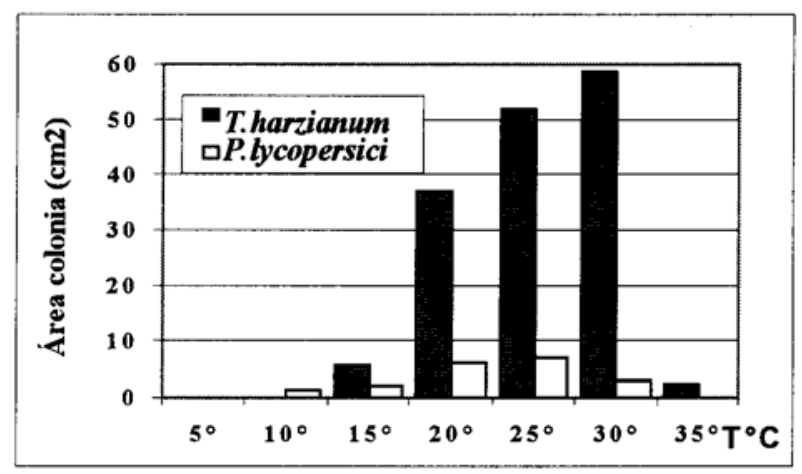

Figura 3. Area de crecimiento de colonia de $T$. harzianum (promedio 5 cepas) y de $P$. lycopersici (promedio 5 cepas) a diferentes temperaturas.

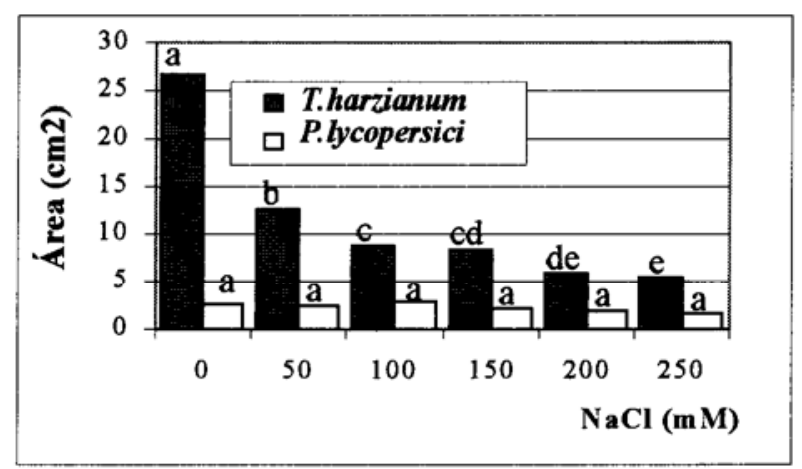

Figura 4. Desarrollo de áreas de colonias de T.harzianum (promedio 5 cepas) y P.lycopersici (promedio de 5 cepas) a concentraciones crecientes de sal $(\mathrm{mM} \mathrm{NaCl})$ Promedios con letras iguales no presentan diferencias significativas a $P=0,05$, de acuerdo con test de Duncan.

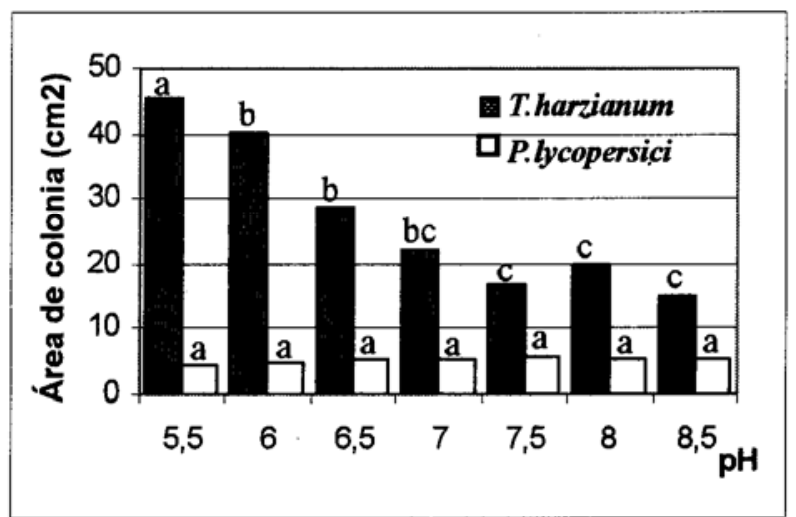

Figura 5. Desarrollo de áreas de colonias de T.harzianum (promedio 5 cepas) y P.lycopersici (promedio de 5 cepas) a distintos pH. Promedios con letras iguales no presentan diferencias significativas a $P=0,05$, de acuerdo con test de Duncan 

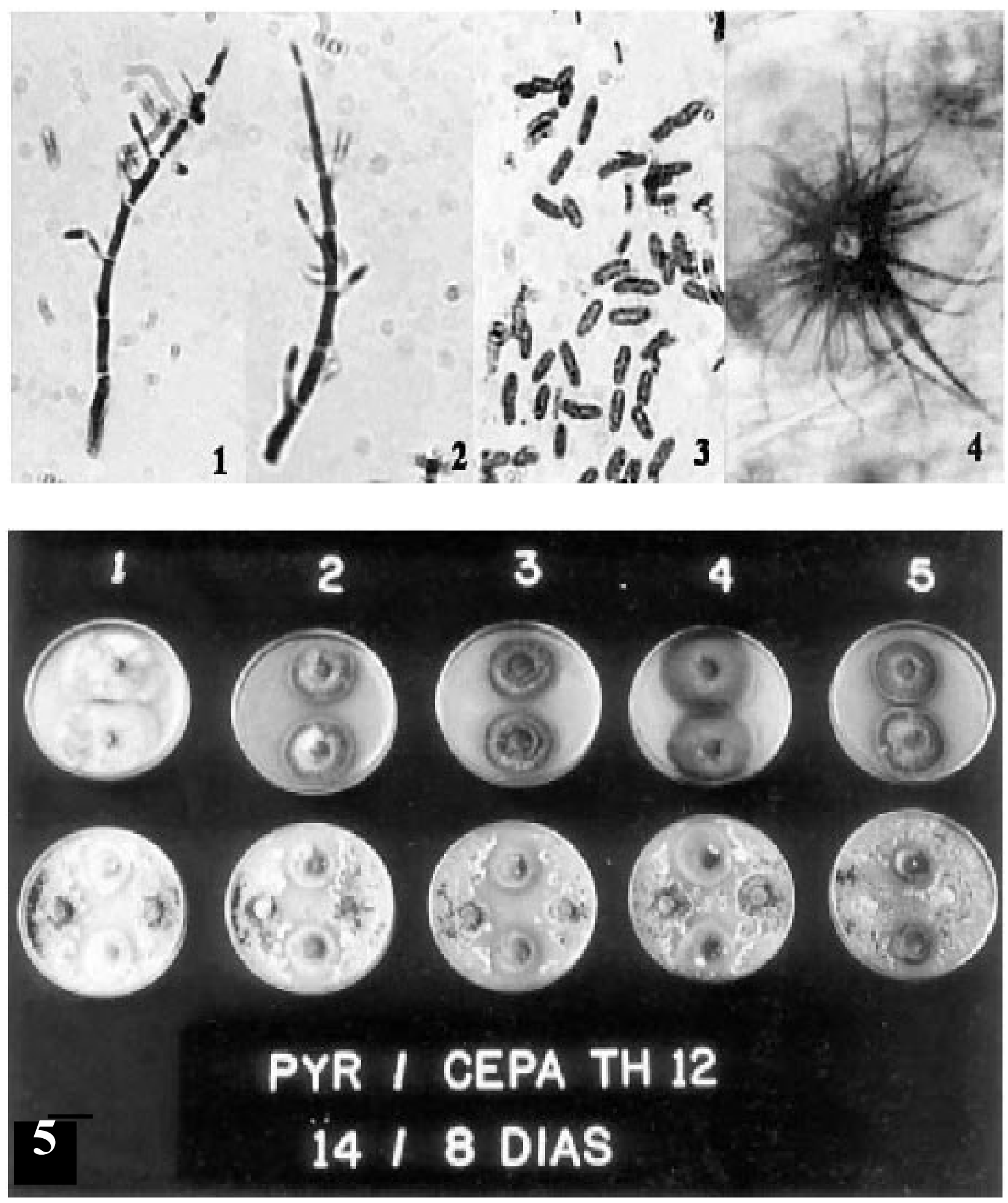

Figura 1. Pyrenochaeta lycopersici: 1 y 2.- Conidióforos simples, septados, con formación de conidios en la base del septo 1000x . 3.- Conidios hialinos, unicelulares 1000x. 4.-Setas alrededor del ostíolo 200x. 5.- Prueba dual entre $\boldsymbol{T}$. harzianum (cepa Th12) y 5 cepas de $\boldsymbol{P}$. lycopersici, sembradas a los 8 y 14 días, respectivamente. Obsérvese el grado de inhibición del crecimiento micelial y de sobrecrecimiento del biocontrolador. 
Tabla 3.- Ensayo en invernadero, con cepas de Trichoderma y Bromuro de metilo, en el control de raíz corchosa de plantas de tomate en macetas con suelo infectado en forma natural con P.lycopersici.

\begin{tabular}{|c|c|c|c|c|}
\hline Tratamiento & $\begin{array}{c}\text { Indice de } \\
\text { dano* }\end{array}$ & $\begin{array}{c}\text { Peso de raices } \\
\text { materia seca (g) }\end{array}$ & $\begin{array}{c}\text { Peso aéreo materia } \\
\text { seca (g) }\end{array}$ & $\begin{array}{c}\text { Altura de } \\
\text { plantas (cm) }\end{array}$ \\
\hline T0 & $4,25 \mathrm{a}$ & $1,63 \mathrm{a}$ & $19,47 \mathrm{a}$ & $0,70 \mathrm{a}$ \\
\hline $\mathbf{T 1}$ & $0,63 \mathrm{c}$ & $4,8 \mathrm{c}$ & $46,51 \mathrm{c}$ & $0,90 \mathrm{~b}$ \\
\hline $\mathbf{T}$ & $3,25 \mathrm{~b}$ & $1,7 \mathrm{a}$ & $20,55 \mathrm{ab}$ & $0,71 \mathrm{a}$ \\
\hline $\mathbf{T}$ & $3,25 \mathrm{~b}$ & $2,59 \mathrm{~b}$ & $27,40 \mathrm{~b}$ & $0,79 \mathrm{ab}$ \\
\hline $\mathbf{T 4}$ & $3,25 \mathrm{~b}$ & $2,35 \mathrm{ab}$ & $25,25 \mathrm{ab}$ & $0,75 \mathrm{a}$ \\
\hline $\mathbf{T}$ & $3,25 \mathrm{~b}$ & $2,25 \mathrm{ab}$ & $19,05 \mathrm{a}$ & $0,72 \mathrm{a}$ \\
\hline $\mathbf{T}$ & $3,5 \mathrm{ab}$ & $2,41 \mathrm{ab}$ & $22,50 \mathrm{ab}$ & $0,70 \mathrm{a}$ \\
\hline $\mathbf{T}$ & $3,5 \mathrm{ab}$ & $1,69 \mathrm{ab}$ & $20,86 \mathrm{ab}$ & $0,72 \mathrm{a}$ \\
\hline
\end{tabular}

T0: Sin tratamiento(control); T1: Bromuro de metilo más cloropicrina(98:2) en dosis de 70g/m2;T2: cepa Th11 en dosis de 5\%; T3: cepa Th11 en dosis de 10\%; T4: cepa Th12 en dosis de 5\%; T5 cepa Th12 en dosis de 10\%; T6: cepa Th16 en dosis de 5\%; T7: cepa Th16 en dosis de 10\%. (Letras distintas corresponden a diferencias significativas al 5\%)

plementario (Perez et al.2002), la habilidad de las cepoas esta dada no solo por su capacidad para producir compuestos volátiles, sino por su alta secreción de endoquitinasa. Este aspecto se puede visualizar en la figura le, donde la cepa Th12 no solo inhibe el crecimiento micelial sino que además crece sobre las diferentes colonias de $\boldsymbol{P}$. lycopersici.

Características de $\mathrm{T}^{\circ}, \mathrm{pH}$ y Salinidad de aislados de $P$. lycopersici y $T$. harzianum. En general, se observa que ambas especies de hongos presentaron un mayor crecimiento micelial a temperaturas superiores a $20^{\circ} \mathrm{C}$, con un óptimo de crecimiento para $\boldsymbol{T}$. harzianum entre los 25 y $30^{\circ} \mathrm{C}$, esto coincide con lo observado por Danielson \& Davey (1973), quienes determinan como rango óptimo para $T$. harzianum en $27^{\circ} \mathrm{C}$, con un máximo a los $32^{\circ} \mathrm{C}$. Por otro lado, para $P$. lycopersici su óptimo de crecimiento se encontró entre los 20 y $25^{\circ} \mathrm{C}$, no observándose crecimiento bajo los $10^{\circ} \mathrm{C}$ (Figura 3). Tremolen (1962), sostiene que la temperatura óptima para el crecimiento del hongo bajo condiciones in vitro es de aproximadamente $26^{\circ} \mathrm{C}$, pero que la temperatura óptima en el suelo para la infección es de 15 a $20^{\circ} \mathrm{C}$, y que sobre los $20^{\circ} \mathrm{C}$ la severidad de la enfermedad decrece. Esto coincide también con Shishkoff \& Campbell (1990), quienes determinan que la enfermedad es más severa con temperaturas entre 16 y $21^{\circ} \mathrm{C}$, que a temperaturas de $27^{\circ} \mathrm{C}$. Esto se explicaría ya que $\boldsymbol{P}$. lycopersici es un parasito ecológicamente obligado, siendo más eficiente que otros patógenos sólo a temperaturas bajas de suelo.

$\mathrm{Al}$ analizar las temperaturas de suelo presentes en cultivos de tomates bajo invernadero en la V Región de Chile, es posible inferir que el control biológico de raíz corchosa podría verse mermado. Este aspecto cobra importancia en un programa de mejoramiento de las cepas de T. harzianum.

Al analizar los resultados obtenidos se observa que Trichoderma se afecta en forma significativa con el aumento de salinidad en el medio, reduciéndo su crecimiento en un $53,8 \%$ a la concentración de $50 \mathrm{mM}$ de $\mathrm{NaCl}$ (Figura 4). Danielson \& Davey (1973), obtuvieron una alta inhibición general de Trichoderma al utilizar una concentración salina de $5 \% \mathrm{NaCla}(\mathrm{p} / \mathrm{v})$ equivalente a 856 $\mathrm{mM}$. De todos modos es importante considerar que la mayoría de los suelos agrícolas de esta región se encuentran en el rango comprendido entre 0 y $50 \mathrm{mM}$ de $\mathrm{NaCl}$ (Raggi, 2001). Por otro lado, las 5 cepas de Pyrenochaeta, no se vieron afectadas por el aumento de concentración de sales (Figura 4). Este es un aspecto que también debe ser considerado en un programa de mejoramiento de las cepas de Trichoderma.

En relación al rango óptimo de $\mathrm{pH}$ para Trichoderma, se observa que éste oscila, para el rango evaluado, entre los pH 5,5 y 6, afectándose en más de un $60 \%$ su área de crecimiento cuando el $\mathrm{pH}$ es 7,5 o superior ( Figura 5). Esto concuerda con los resultados de Hadar et al. (1984), donde el mayor crecimiento se obtuvo alrededor de $\mathrm{pH} 4,5$, declinando notablemente su crecimiento a pH 8,0. En Pyrenochaeta, no se observó efecto significativo en su crecimiento con valores altos de $\mathrm{pH}$, lo que podría explicar su agresividad bajo las condiciones de suelo de Quillota, donde los valores de pH oscilan entre 7,5 y 8,0. De hecho, en el ensayo bajo condiciones de invernadero, se empleó suelo naturalmente infectado con $\mathrm{pH}$ igual a 7,7.

Ensayo de invernadero. Al efectuar el ensayo en plan- 

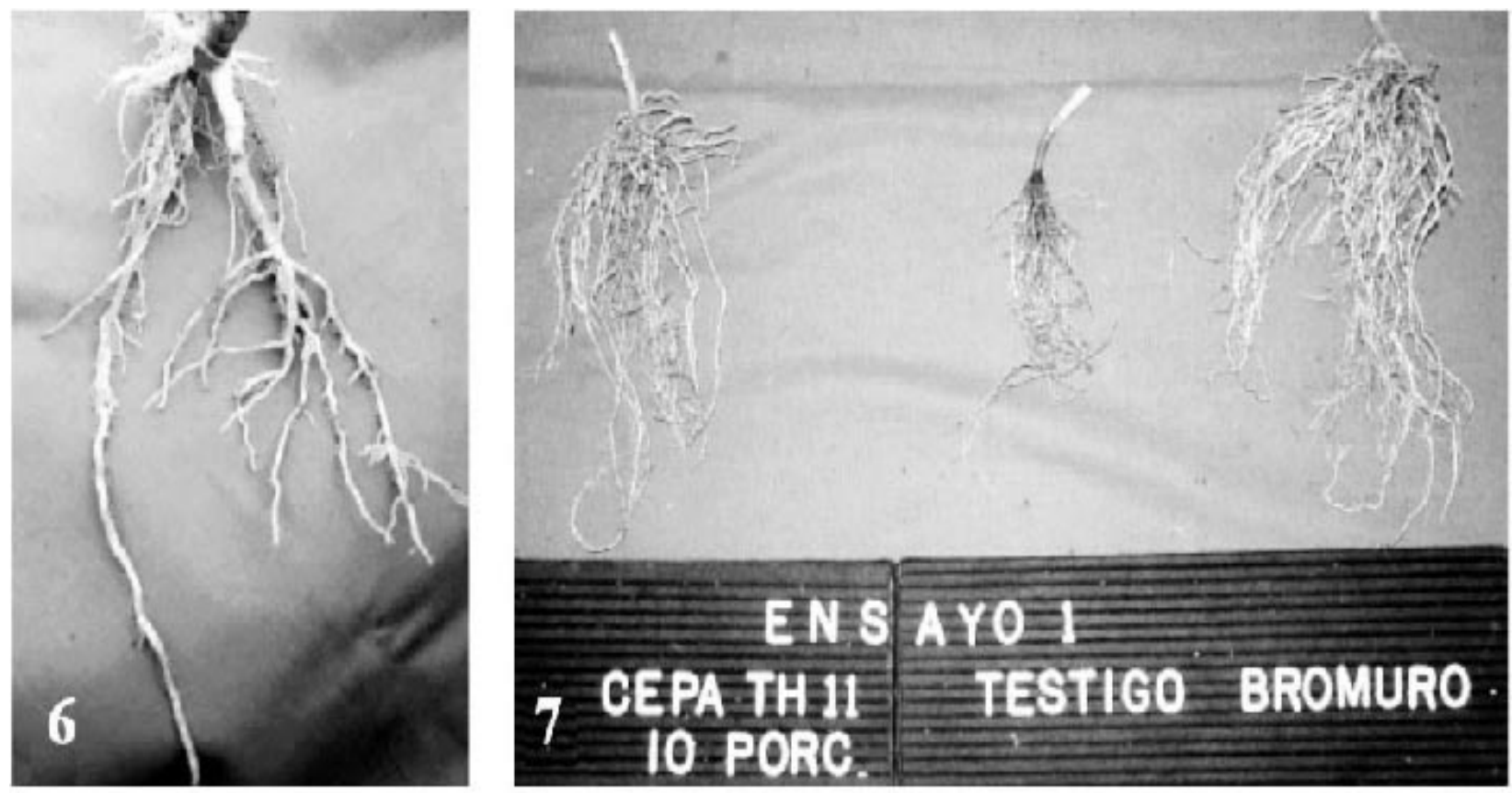

Figura 2.- 6.- Raíz de tomate con notorias lesiones corchosas intermitentes. 7.- Raíces de tomate (izq.) inoculadas con cepa Th 11 (dosis 10\%) en comparación a tratamiento con $\mathrm{CH} 3 \mathrm{Br}$ y testigo inoculado

en invernaderos fríos en predios de diferentes localidades de la V Región de Chile. De acuerdo a las observaciones morfológicas efectuadas, las estructuras reproductivas de esta especie se ajustan a las dimensiones originalmente descritas por Schneider y Gerlach (1966) para este hongo patógeno. Tanto en los ensayos efectuados a nivel de laboratorio como bajo condiciones controladas de invernadero, se determinó que Tricho-derma harzianum podría considerarse apropiada para el control biológico de esta enfermedad, destacándose la cepa Th11 en el ensayo de invernadero, al emplearse la dosis más alta (10\%).

Annual Phytopathology $8: 9-15$

\section{REFERENCIAS}

Araya, M. (1994). Prospección de raíz del tomate (Lycopersicon esclulentum Mill) causada por Pyrenochaeta lycopersici (Gerlach \& Schneider), en la provincia de Quillota y caracterización de las diferentes cepas obtenidas. Taller de Licenciatura Ing. Agr. Quillota, Universidad Católica de Valparaíso, Facultad de Agronomía.

Campbell, R.; Schweers, V. \& Hall, D. (1982). Corky root in California caused by Pyrenochaeta lycopersici and control by soil fumigation. Plant Disease 66: 657-661

Clerjeau, M. (1976). Exigences thermiques de croissance et d agressivité de divers isolats de Pyrenochaeta lycopersici Schneider et Gerlach.

Danielson, R.M. \& Davey, C.B. (1973). Effect of nutrient and acidity on phialospore germination in culture. Soil Biology and Biochemistry 5: 517-524

Gonzalez, J.M. (1991). Efecto de la aplicación Bravo (i. a. clorotaloni), Previcur (i. a. propamocarb) y ácido fosforoso sobre la incidencia de Pyrenochaeta lycopersici y Phytophthora spp. en tomate cultivado para otoño en invernadero. Taller de Licenciatura Ing. Agr. Quillota, Universidad Católica de Valparaíso, Facultad de Agronomía.

Last, F. \& Ebber, M. H. (1996). The epidemiology of tomato brown root rot. Annual Applied Biology 57: 95-112

Montealegre, J.; .Fuentes, P. \& Henriquez, J.L. (1995). Efecto de la solarización y fumigación en el control de Pyrenochaeta lycopersici y su relación con el rendimiento y calidad de un cultivo de tomates. Fitopatología 31: 217-229

Ocon,Y.;Chet,I. \& Henis,Y. (1973). Effects of lactose ethanol and cicloheximide on the translocation patterns of radioactive compopunds and of sclerotium formation in Sclerotium rolfsii. J.Gen- Mycrobiol.74:251-258

Olavarría, L. \& Besoain, X.A. (1990). determinación del agente causal de la enfermedad raíz corchosa en tomate (Lycopersicon esculentum Mill). Simiente 60: 176-177

Opazo, M. (1997). Búsqueda de microorganismos como potenciales biocontroladores de Pyrenochaeta lycopersici (Scheneidr \& Gearlach) causante de la ríz corchosa en el cultivo de tomate. Taller de Licenciatura Ing. Agr. Quillota, Universidad Católica de Valparaíso, Facultad de Agronomía.

Pérez, L.; Besoain, X. \& Reyes, M. (2002). The expression of extracellular fungal cell wall hydrolytic enzymes in different Trichoderma 
harzianum isolates correlates with their ability to control Pyrenochaeta lycopersici. Biol. Res., 35:.401-410

Punithalingam, E. \& Holliday, P. (1973). CMI. Description of pathogenic fungi and bacteria. England, Commonwealth Mycological Institute. 40:398

Raggi, C. (2001). Control biológico de Pyrenochaeta lycopersici bajo condiciones in vitro y de invernadero mediante el uso de aislados de Trichoderma spp. y de solarización. Taller de Licenciatura. Ing. Agr. Quillota, Universidad Católica de Valparaíso, Facultad de Agronomía.

Snaider,R. \& Gerlach, W. (1966). Pyreonochaeta lycopersici nov. spec., der Erreger der Korkwurzelkrankheit der tomate. Phytopath. Z.56:117-122

Shishkoff, N. \& Cambell, R. (1990). Survival of Pyrenochaeta lycopersici and the influence of temperature and cultivar reistence on the development of corky root of tomato. Plant Disease 74: 889-894

Silvan, A.; Ucko, O \& Chet, I. (1987). Biological control of Fusarium crown rot of tomato by Trichoderma harzianum under field conditions. Plant Disease 71:587-592

Sutton, B.C. (1980). The Coelomycetes. Fungi imperfecti with pycnidia acervuli and stromata. Commonwealth Mycological Institute. Kew, Surrey, England.
Termohlen, I. (1962). Onderzoekingen over Kurkwortel bij tomaat en over deKurkwortel-schimmel. Tijdschr. Plantenaiekten 68:295-367 